\title{
Involvement of Fibroblast Growth Factor Receptor Genes in Benign Prostate Hyperplasia in a Korean Population
}

\author{
Hae Jeong Park, ${ }^{1}$ Su Kang Kim, ${ }^{1}$ Jong Woo Kim, ${ }^{1}$ \\ Sang Hyub Lee, ${ }^{2}$ Koo Han Yoo, ${ }^{2}$ and Joo-Ho Chung ${ }^{1}$ \\ ${ }^{1}$ Kohwang Medical Research Institute, School of Medicine, Kyung Hee University, 26 Kyunghee-daero, \\ Dongdaemun-gu, Seoul 130-701, Republic of Korea \\ ${ }^{2}$ Department of Urology, School of Medicine, Kyung Hee University, 26 Kyunghee-daero, Dongdaemun-gu, \\ Seoul 130-701, Republic of Korea \\ Correspondence should be addressed to Joo-Ho Chung; hjpark17@gmail.com
}

Received 3 September 2013; Revised 1 November 2013; Accepted 15 November 2013

Academic Editor: Lance A. Liotta

Copyright (C) 2013 Hae Jeong Park et al. This is an open access article distributed under the Creative Commons Attribution License, which permits unrestricted use, distribution, and reproduction in any medium, provided the original work is properly cited.

\begin{abstract}
Fibroblast growth factors (FGFs) and their receptors (FGFRs) have been implicated in prostate growth and are overexpressed in benign prostatic hyperplasia (BPH). In this study, we investigated whether single nucleotide polymorphisms (SNPs) of the FGFR genes (FGFR1 and FGFR2) were associated with $\mathrm{BPH}$ and its clinical phenotypes in a population of Korean men. We genotyped four SNPs in the exons of FGFR1 and FGFR2 (rs13317 in FGFR1; rs755793, rs1047100, and rs3135831 in FGFR2) using direct sequencing in $218 \mathrm{BPH}$ patients and 213 control subjects. No SNPs of FGFR1 or FGFR2 genes were associated with BPH. However, analysis according to clinical phenotypes showed that rs1047100 of FGFR2 was associated with prostate volume in BPH in the dominant model (GA/AA versus GG, $P=0.010$ ). In addition, a significant association was observed between rs13317 of FGFR1 and international prostate symptom score (IPSS) in the additive (TC versus CC versus TT, $P=0.0022$ ) and dominant models (TC/CC versus TT, $P=0.005)$. Allele frequency analysis also showed significant association between rs13317 and IPSS $(P=$ 0.005). These results suggested that FGFR genes could be related to progression of BPH.
\end{abstract}

\section{Introduction}

Benign prostatic hyperplasia (BPH) is the most common urological problem associated with aging in men. Onequarter of men in their 50s, one-third in their 60 s, and half of men older than 80 have BPH [1]. BPH is characterized by hyperplasia of prostatic stromal and epithelial cells, and it manifests as a severe obstruction in urinary flow with discomfort and pain. The pathogenesis of $\mathrm{BPH}$ is not completely understood; however, the most significant risk factors for the development of BPH are androgen level and aging [2]. Growth factors and their receptors, including members of the fibroblast growth factor (FGF) family, insulin-like growth factor (IGF) family, epithelial growth factor (EGF) family, and transforming growth factor $\beta$ (TGFB), which regulate the growth of prostatic stromal and epithelial cells, are also involved in the pathogenesis of $\mathrm{BPH}$ [3-5].

Genetic strategies have been used over the past few decades to investigate BPH. In particular, studies have shown that polymorphisms of growth factors and their receptor genes are associated with $\mathrm{BPH}$. Indeed, previous studies have reported that a codon 10 polymorphism in TGFB1 was associated with the development of BPH in Japanese [6] and Iranian populations [7], suggesting the importance of the TGF pathway in the development of prostatic diseases. Mullan et al. [8] reported a significant association of a codon 10 polymorphism in TGFB1 with treatment for $\mathrm{BPH}$, and an association of a CA-repeat polymorphismin EGFR with international prostate symptom score (IPSS) in BPH. Moreover, a CA-repeat polymorphism of 19-allele in IGF1 appears to increase the risk of $\mathrm{BPH}$ with a gene dosage effect in the Japanese population [9]. However, despite a widespread consensus on the involvement of growth factors in prostatic growth, attempts to address growth factor gene polymorphisms in patients with BPH have been limited.

FGFs are involved in multiple biological processes such as differentiation, motility, and proliferation and mediate their 
cellular responses by activating a family of four receptor tyrosine kinases, FGFR1 through FGFR4 [10]. FGFRs are present in various organs. In the human prostate, FGFR1-3 are abundantly expressed in the prostate stroma and/or epithelium [11-14], and FGFR4 has relatively low expression in the epithelium [15]. In the prostate, FGFRs play an important role in prostate organogenesis, and perturbations in FGFR expression have been potently implicated in prostatic disease [11]. Previous studies have reported that overexpression of FGFRs is important in the development of BPH [16-18]. Indeed, FGFR1 was observed to be increased in the stroma of $\mathrm{BPH}$ patients compared to that from normal prostates $[16,17]$, and increased expression of FGFR2 has been detected in $\mathrm{BPH}$ [18]. Furthermore, although no studies have reported changes in expression of FGFR4 in $\mathrm{BPH}$, a genetic study showed a significant association between FGFR4 polymorphisms and $\mathrm{BPH}$ in a Japanese population [19]. In light of these findings, we postulated that FGFRs may be involved in the pathogenesis of BPH. In this study, we investigated the genetic associations between $\mathrm{BPH}$ and the FGFR genes (FGFR1 and FGFR2) in Korean BPH patients by analyzing single nucleotide polymorphisms (SNPs) of the FGFR genes.

\section{Methods}

2.1. Subjects. A total of 233 male patients with $\mathrm{BPH}$ (mean age \pm standard deviation, $65.77 \pm 9.46$ years) and 213 male control subjects (mean age, $61.89 \pm 8.26$ years) were enrolled. All patients with $\mathrm{BPH}$ were from Kyung Hee University Hospital between January 2002 and December 2008, and in all patients, lower urinary tract symptoms were quantified using IPSS. Uroflowmetry was performed to measure peak urinary flow rate $\left(Q_{\max }\right)$ for all patients. Serum prostatespecific antigen (PSA) level was measured in all $\mathrm{BPH}$ patients. Patients with serum PSA level more than $4 \mathrm{ng} / \mathrm{mL}$ underwent transrectal ultrasound-guided prostate biopsy to rule out prostate cancer. Prostate size was assessed using transrectal ultrasound. Patients with prostate cancer, neurogenic bladder, urinary tract infection, uncontrolled diabetes mellitus, or cardiovascular disease were excluded. The clinical characteristics of $\mathrm{BPH}$ patients are summarized in Table 1. To determine the relationship between polymorphisms of FGFR genes and clinical phenotypes, $\mathrm{BPH}$ patients were divided into subgroups according to prostate volume $(<30 \mathrm{~mL}$ or $\geq 30$ $\mathrm{mL})$, PSA level $(<1.5$ or $\geq 1.5 \mathrm{ng} / \mathrm{mL})$, IPSS $(<20$ or $\geq 20)$, and $\left(Q_{\max }\right)(<10$ or $\geq 10 \mathrm{~mL} / \mathrm{sec})[20,21]$.

Normal healthy controls were recruited from men visiting the hospital for routine health checkups. All healthy control subjects underwent screening and had a normal PSA level $(<4.0 \mathrm{ng} / \mathrm{mL})$. They showed no clinical evidence of $\mathrm{BPH}$, neurogenic bladder, urinary tract infection, diabetes mellitus, cardiovascular disease, or any other severe diseases.

Written informed consent was obtained from all patients and control subjects for the use of clinical data and samples, including DNA extracted from peripheral blood. The Institutional Review Board at Kyung Hee University Medical Center approved the protocol for this study.
TABLE 1: Clinical characteristics of benign prostatic hyperplasia $(\mathrm{BPH})$ patients and control subjects.

\begin{tabular}{lcc}
\hline & BPH & Control \\
\hline No. of subjects & 233 & 213 \\
Age (mean \pm S.D.) & $65.77 \pm 9.46$ & $61.89 \pm 8.26$ \\
Prostate volume $(\mathrm{mL})$ & & \\
$\quad$ Total & $38.34 \pm 21.38$ & \\
$\quad$ Inner & $17.99 \pm 18.60$ & \\
PSA (ng/mL) & & \\
$\quad$ Total & $4.38 \pm 5.24$ & \\
$\quad$ Free & $0.99 \pm 1.22$ & \\
IPSS & $17.05 \pm 7.66$ & \\
QoL & $3.61 \pm 1.34$ & \\
Uroflowmetry $(\mathrm{mL} / \mathrm{s})$ & $11.33 \pm 5.77$ & \\
$\quad Q_{\text {max }}$ & $6.46 \pm 3.67$ & \\
$\quad Q_{\text {avg }}$ & $109.00 \pm 148.33$ \\
VV (mL) & $57.59 \pm 98.68$ & \\
PVR (mL) &
\end{tabular}

PSA: prostate-specific antigen; IPSS: international prostate symptom score; QoL: quality of life; $Q_{\max }$ : peak urinary flow rate; $Q_{\text {avg }}$ : average urinary flow rate; VV: voided volume; PVR: postvoid residual urine.

2.2. SNP Selection and Genotyping. SNPs located in the exons $\left[5^{\prime}\right.$-untranslated region (UTR), coding region, and $3^{\prime}$ UTR] of the FGFR1 and FGFR2 genes were selected from the National Center for Biotechnology Information SNP database (http://www.ncbi.nlm.nih.gov/projects/SNP/, BUILD 137). We excluded SNPs without data on genotype frequency, and those with a minor allele frequency (MAF) $<0.05$ in Chinese and Japanese populations. Finally, we selected four SNPs [rs13317 (T/C, 3'UTR) for FGFR1; rs755793 (Met186Thr), rs1047100 (Val232Val) and rs3135831 (C/T, $3^{\prime}$ UTR) for FGFR2]. DNA was isolated from peripheral blood samples using a DNA Isolation Kit for blood (Roche, IN, USA). SNP genotyping was conducted by direct sequencing using specific primers for rs13317 (sense: $5^{\prime}$-CCAACTTAGTGAAACCCCATCT-3' ; antisense: $5^{\prime}$-CCCAACAAATACAGTCTGGTCA-3'), rs755793 (sense: $5^{\prime}$-TACTCATGGAGGGGAAGCTG-3'; antisense: $5^{\prime}$-CTGACATGGGCAATTGTGAC-3'), rs1047100 (sense: 5' -CATACCTTTCTTGCCTCCTTCA-3'; antisense: $5^{\prime}$-CAGAAGCAGCCTTGTAAAATGA- $3^{\prime}$ ) and rs3135831 (sense: $5^{\prime}$-TGTATTTCCCAAACCTCTGTCC- $3^{\prime}$; antisense: $5^{\prime}$-CACTGTCAAGGCTATAAACTGC- ${ }^{\prime}$ ). PCR products were sequenced using an ABI PRISM 3730XL analyzer (PE Applied Biosystems, Foster City, CA, USA). Sequence data were analyzed using SeqManII software (DNASTAR Inc., Madison, WI, USA).

2.3. Statistical Analysis. SNPStats (http://bioinfo.iconcologia .net/index.php) and SPSS 18.0 software (SPSS Inc., Chicago, IL, USA) were used to analyze genetic data and determine Hardy-Weinberg equilibrium (HWE). Associations between SNPs and BPH, as well as any associations between the SNPs and BPH subgroups, were estimated by computing odds ratios (ORs) and 95\% confidence intervals (CIs) with logistic regression analysis, controlling for age 
TABLE 2: Frequencies of the genotypes and alleles of polymorphisms of FGFR genes in BPH patients and control subjects.

\begin{tabular}{|c|c|c|c|c|c|c|c|}
\hline Gene & SNP & Genotype/allele & $\begin{array}{c}\text { Control } \\
n=213(\%)\end{array}$ & $\begin{array}{c}\mathrm{BPH} \\
n=233(\%)\end{array}$ & Models & OR $(95 \% \mathrm{CI})$ & $P$ \\
\hline \multirow{5}{*}{ FGFR1 } & \multirow{5}{*}{ rs13317 } & $\mathrm{T} / \mathrm{T}$ & $85(39.9)$ & $83(35.6)$ & Additive & $1.11(0.83-1.47)$ & 0.48 \\
\hline & & $\mathrm{T} / \mathrm{C}$ & $100(47.0)$ & $116(49.8)$ & Dominant & $1.16(0.79-1.72)$ & 0.45 \\
\hline & & $\mathrm{C} / \mathrm{C}$ & $28(13.2)$ & $34(14.6)$ & Recessive & $1.09(0.63-1.90)$ & 0.75 \\
\hline & & $\mathrm{T}$ & $270(63.4)$ & $282(60.5)$ & & 1 & \\
\hline & & $\mathrm{C}$ & $156(36.6)$ & $184(39.5)$ & & $1.13(0.86-1.48)$ & 0.38 \\
\hline \multirow{15}{*}{ FGFR2 } & \multirow{5}{*}{ rs755793 } & $\mathrm{T} / \mathrm{T}$ & $193(90.6)$ & $208(89.3)$ & Additive & $1.08(0.59-2.00)$ & 0.80 \\
\hline & & $\mathrm{T} / \mathrm{C}$ & $20(9.4)$ & $24(10.3)$ & Dominant & $1.04(0.55-1.96)$ & 0.90 \\
\hline & & $\mathrm{C} / \mathrm{C}$ & $0(0.0)$ & $1(0.4)$ & Recessive & NA (0.00-NA) & NA \\
\hline & & $\mathrm{T}$ & $406(95.3)$ & $440(94.4)$ & & 1 & \\
\hline & & $\mathrm{C}$ & $20(4.7)$ & $26(5.6)$ & & $1.20(0.66-2.18)$ & 0.55 \\
\hline & \multirow{5}{*}{ rs 1047100} & $\mathrm{G} / \mathrm{G}$ & $193(90.6)$ & $196(84.1)$ & Additive & $1.92(1.07-3.43)$ & 0.024 \\
\hline & & $\mathrm{G} / \mathrm{A}$ & $20(9.4)$ & $35(15.0)$ & Dominant & $1.89(1.04-3.45)$ & 0.034 \\
\hline & & $\mathrm{A} / \mathrm{A}$ & $0(0.0)$ & $2(0.9)$ & Recessive & NA (0.00-NA) & NA \\
\hline & & G & $406(95.3)$ & 427 (91.6) & & 1 & \\
\hline & & A & $20(4.7)$ & $39(8.4)$ & & $1.85(1.06-3.23)$ & 0.029 \\
\hline & \multirow{5}{*}{ rs3135831 } & $\mathrm{C} / \mathrm{C}$ & $92(43.2)$ & $116(49.8)$ & Additive & $0.83(0.63-1.09)$ & 0.17 \\
\hline & & $\mathrm{C} / \mathrm{T}$ & 88 (41.3) & $90(38.6)$ & Dominant & $0.80(0.55-1.18)$ & 0.26 \\
\hline & & $\mathrm{T} / \mathrm{T}$ & $33(15.5)$ & 27 (11.6) & Recessive & $0.72(0.41-1.25)$ & 0.24 \\
\hline & & $\mathrm{C}$ & $272(63.8)$ & $322(69.1)$ & & 1 & \\
\hline & & $\mathrm{T}$ & $154(36.2)$ & $144(30.9)$ & & $0.79(0.60-1.04)$ & 0.10 \\
\hline
\end{tabular}

as a covariable. In the logistic regression analysis for each SNP, the models assuming additive inheritance (the risk increased $r$-fold for subjects with one minor allele and 2r-fold for subjects with two minor alleles), dominant inheritance (subjects with one or two minor alleles had the same relative risk for the disease), or recessive inheritance (subjects with two minor alleles were at increased risk of the disease) were used. To avoid chance findings due to multiple comparison, the Bonferroni correction was applied by lowering significance levels to $P=0.05 / 4$ for the 4 SNPs.

\section{Results}

All SNPs analyzed in this study were polymorphic, and the genotype distributions of the SNPs were in $\operatorname{HWE}(P>0.05)$. Differences in genotype distributions and allele frequencies for the four SNPs between BPH and control were analyzed. As shown in Table 2, rs1047100 of FGFR2 was associated with $\mathrm{BPH}$ in the additive (GA versus AA versus GG; $P=0.024, \mathrm{OR}$ $=1.92,95 \% \mathrm{CI}=1.07-3.43)$ and dominant models (GA/AA versus $\mathrm{GG} ; P=0.034, \mathrm{OR}=1.89,95 \% \mathrm{CI}=1.04-3.45)$. Allele frequency analysis also showed an association between rs1047100 and $\mathrm{BPH}(P=0.029$, OR $=1.85,95 \% \mathrm{CI}=1.06-$ 3.23). However, the statistical significance did not remain after Bonferroni correction.

We further analyzed the associations between SNPs and the clinical phenotypes of BPH (prostate volume, PSA level,
IPSS, and $\left.Q_{\max }\right)$. In analysis according to small or large prostate volume $(<30$ or $\geq 30 \mathrm{~mL})$, we found that $\mathrm{rs} 1047100$ of FGFR2 was significantly associated with prostate volume in the additive (GA versus AA versus GG; $P=0.016, \mathrm{OR}=0.43$, 95\% CI $=0.21-0.87$ ) and dominant models (GA/AA versus GG; $P=0.010, \mathrm{OR}=0.38,95 \% \mathrm{CI}=0.18-0.81$ ) (Table 3 ). However, statistical significance was only maintained in the dominant model after Bonferroni correction. The frequency of genotypes containing the A allele was lower in $\mathrm{BPH}$ patients with large prostate volume $(\mathrm{GA}=9.6 \%, \mathrm{AA}=0.8 \%)$, compared to those with small prostate volume $(\mathrm{GA}=21.5 \%$, $\mathrm{AA}=0.9 \%)$. Although allele frequency analysis also revealed that $\mathrm{rs} 1047100$ was associated with prostate volume $(P=$ 0.021 , OR $=0.45,95 \% \mathrm{CI}=0.23-0.89)$, this result was not significant after Bonferroni correction.

We also found a significant association between rs13317 of FGFR1 and IPSS in an analysis according to low or high IPSS ( $<20$ or $\geq 20)$. As shown in Table 4 , rs13317 of FGFR1 was associated with IPSS in the additive (TC versus CC versus TT, $P=0.0022, \mathrm{OR}=0.50,95 \% \mathrm{CI}=0.32-0.79)$ and dominant models (TC/CC versus TT, $P=0.005, \mathrm{OR}=0.43,95 \%$ $\mathrm{CI}=0.23-0.78)$. Allele frequency analysis also revealed that rs13317 of FGFR1 was associated with IPSS $(P=0.005$, OR $=0.55,95 \% \mathrm{CI}=0.36-0.84)$. In particular, the frequency of the $\mathrm{C}$ allele was decreased in BPH patients with high IPSS $(30.3 \%)$ compared to those with low IPSS (44.2\%). These results remained significant after Bonferroni correction. 
TABLE 3: Frequencies of the genotypes and alleles of polymorphisms of FGFR genes, based on small and large prostate volume, in subjects with $\mathrm{BPH}$.

\begin{tabular}{|c|c|c|c|c|c|c|c|}
\hline \multicolumn{8}{|c|}{ Prostate volume $(\mathrm{mL})$} \\
\hline Gene & SNP & Genotype/allele & $\begin{array}{c}<30 \\
n=107(\%)\end{array}$ & $\begin{array}{c}\geq 30 \\
n=125(\%)\end{array}$ & Models & OR (95\% CI) & $P$ \\
\hline \multirow{5}{*}{ FGFR1 } & \multirow{5}{*}{ rs13317 } & $\mathrm{T} / \mathrm{T}$ & $36(33.6)$ & $46(36.8)$ & Additive & $1.03(0.69-1.52)$ & 0.89 \\
\hline & & $\mathrm{T} / \mathrm{C}$ & $58(54.2)$ & $58(46.4)$ & Dominant & $0.88(0.50-1.53)$ & 0.64 \\
\hline & & $\mathrm{C} / \mathrm{C}$ & $13(12.2)$ & $21(16.8)$ & Recessive & $1.41(0.66-3.01)$ & 0.38 \\
\hline & & $\mathrm{T}$ & $130(60.7)$ & $150(60.0)$ & & 1 & \\
\hline & & $\mathrm{C}$ & $84(39.3)$ & $100(40.0)$ & & $1.03(0.71-1.50)$ & 0.87 \\
\hline \multirow{15}{*}{ FGFR2 } & \multirow{5}{*}{ rs755793 } & $\mathrm{T} / \mathrm{T}$ & $93(86.9)$ & $114(91.2)$ & Additive & $0.54(0.24-1.21)$ & 0.13 \\
\hline & & $\mathrm{T} / \mathrm{C}$ & $13(12.2)$ & $11(8.8)$ & Dominant & $0.55(0.23-1.30)$ & 0.17 \\
\hline & & $\mathrm{C} / \mathrm{C}$ & $1(0.9)$ & $0(0.0)$ & Recessive & $0.00(0.00-\mathrm{NA})$ & NA \\
\hline & & $\mathrm{T}$ & $199(93.0)$ & $239(95.6)$ & & 1 & \\
\hline & & $\mathrm{C}$ & $15(7.0)$ & $11(4.4)$ & & $0.61(0.27-1.36)$ & 0.23 \\
\hline & \multirow{5}{*}{ rs1047100 } & G/G & $83(77.6)$ & $112(89.6)$ & Additive & $0.43(0.21-0.87)$ & 0.016 \\
\hline & & $\mathrm{G} / \mathrm{A}$ & $23(21.5)$ & $12(9.6)$ & Dominant & $0.38(0.18-0.81)$ & 0.010 \\
\hline & & $\mathrm{A} / \mathrm{A}$ & $1(0.9)$ & $1(0.8)$ & Recessive & $0.70(0.04-11.33)$ & 0.80 \\
\hline & & G & $189(88.3)$ & $236(94.4)$ & & 1 & \\
\hline & & $\mathrm{A}$ & $25(11.7)$ & $14(5.6)$ & & $0.45(0.23-0.89)$ & 0.021 \\
\hline & \multirow{5}{*}{ rs3135831 } & $\mathrm{C} / \mathrm{C}$ & $50(46.7)$ & $65(52)$ & Additive & $0.92(0.63-1.36)$ & 0.68 \\
\hline & & $\mathrm{C} / \mathrm{T}$ & $44(41.1)$ & $46(36.8)$ & Dominant & $0.88(0.52-1.49)$ & 0.62 \\
\hline & & $\mathrm{T} / \mathrm{T}$ & $13(12.2)$ & $14(11.2)$ & Recessive & $0.96(0.42-2.17)$ & 0.91 \\
\hline & & $\mathrm{C}$ & $144(67.3)$ & $176(70.4)$ & & 1 & \\
\hline & & $\mathrm{T}$ & $70(32.7)$ & $74(29.6)$ & & $0.87(0.58-1.28)$ & 0.47 \\
\hline
\end{tabular}

Bold characters represent statistically significant values $(P<0.05 / 4)$.

In analysis according to other clinical phenotypes (PSA level and $Q_{\max }$ ), we were not able to find any association of polymorphisms in the FGFR genes (data not shown).

\section{Discussion}

We examined the association of polymorphisms of FGFR1 and FGFR2 with $\mathrm{BPH}$ and its clinical phenotypes in a Korean population. No significant association was detected between polymorphisms of FGFR1 and FGFR2, and BPH. However, in analysis according to clinical phenotypes, we found associations between rs 1047100 of FGFR2 and prostate volume and between rs13317 of FGFR1 and IPSS.

$\mathrm{BPH}$ is a progressive disease found in many men, and numerous factors, including androgen level and aging, have been linked with the risk of BPH progression [22-24]. Prostate volume is the most extensively studied risk factor for $\mathrm{BPH}$ progression $[25,26]$. Indeed, it was reported that men with prostate volume $\geq 30 \mathrm{~mL}$ were more likely to suffer moderate-to-severe symptoms (3.5-fold increase), decreased flow rates (2.5-fold increase), and acute urinary retention (3to 4 -fold increase), compared to men with prostate volume $<30 \mathrm{~mL}$ [27]. Reduced urinary flow, increased IPSS, and increased PSA have been also suggested as predictors of BPH progression [28]. Clinical study demonstrated that men with prostate volume $\geq 31 \mathrm{~mL}, \mathrm{PSA} \geq 1.6 \mathrm{ng} / \mathrm{mL}$, or $Q_{\max }<10.6$ $\mathrm{mL} / \mathrm{sec}$ at baseline had a significantly increased risk of overall clinical progression of BPH [29]. Although IPSS and PSA are simple $\mathrm{BPH}$ diagnostic factors used in the primary care setting, a previous study showed a high correlation between $\mathrm{BPH}$ diagnosed by simple tests (medical history, IPSS, digital rectal examination (DRE), and PSA) and that diagnosed by a full battery of tests including ultrasonographic assessment of residual and prostatic volume, and uroflowmetry [30]. Thus, these factors may also be useful as predictors of BPH progression. In our study, although polymorphisms of FGFR1 and FGFR2 were not associated with PSA level or $Q_{\max }$ in BPH patients, rs1047100 of FGFR2 and rs13317 of FGFR1 were associated with prostate volume and IPSS, respectively. These results indicated that polymorphisms of FGFR1 and FGFR2 may be related to the severity of $\mathrm{BPH}$ and implicated in the progression rather than the incidence of $\mathrm{BPH}$. In particular, we found that the frequency of genotype containing the minor allele, A, of rs1047100 in FGFR2 was lower in BPH patients with large prostate volume than in those with small prostate volume. In addition, the frequency of the minor allele, C, of rs13317 in FGFR1 was significantly decreased in $\mathrm{BPH}$ patients with high IPSS. These finding indicated that patients with genotypes containing the A allele of rs 1047100 or the $\mathrm{C}$ allele of rs13317 may be protected from severe progression of $\mathrm{BPH}$. 
TABLE 4: Frequencies of the genotypes and alleles of polymorphisms of FGFR genes, based on low and high international prostate symptom score (IPSS), in subjects with BPH.

\begin{tabular}{|c|c|c|c|c|c|c|c|}
\hline \multicolumn{8}{|c|}{ IPSS } \\
\hline Gene & SNP & Genotype/allele & $\begin{array}{c}<20 \\
n=130(\%)\end{array}$ & $\begin{array}{c}\geq 20 \\
n=76(\%)\end{array}$ & Models & OR (95\% CI) & $P$ \\
\hline \multirow{5}{*}{ FGFR1 } & \multirow{5}{*}{ rs13317 } & $\mathrm{T} / \mathrm{T}$ & $37(28.5)$ & $36(47.4)$ & Additive & $0.50(0.32-0.79)$ & 0.0022 \\
\hline & & $\mathrm{T} / \mathrm{C}$ & $71(54.6)$ & $34(44.7)$ & Dominant & $0.43(0.23-0.78)$ & 0.005 \\
\hline & & $\mathrm{C} / \mathrm{C}$ & $22(16.9)$ & $6(7.9)$ & Recessive & $0.40(0.15-1.03)$ & 0.044 \\
\hline & & $\mathrm{T}$ & $145(55.8)$ & $106(69.7)$ & & 1 & \\
\hline & & $\mathrm{C}$ & $115(44.2)$ & $46(30.3)$ & & $0.55(0.36-0.84)$ & 0.005 \\
\hline \multirow{15}{*}{ FGFR2 } & \multirow{5}{*}{ rs755793 } & $\mathrm{T} / \mathrm{T}$ & $113(86.9)$ & $70(92.1)$ & Additive & $0.53(0.20-1.37)$ & 0.17 \\
\hline & & $\mathrm{T} / \mathrm{C}$ & $16(12.3)$ & $6(7.9)$ & Dominant & $0.54(0.20-1.44)$ & 0.20 \\
\hline & & $\mathrm{C} / \mathrm{C}$ & $1(0.8)$ & $0(0)$ & Recessive & $0.00(0.00-\mathrm{NA})$ & NA \\
\hline & & $\mathrm{T}$ & $242(93.1)$ & $146(96.1)$ & & 1 & \\
\hline & & $\mathrm{C}$ & $18(6.9)$ & $6(3.9)$ & & $0.55(0.21-1.42)$ & 0.22 \\
\hline & \multirow{5}{*}{ rs1047100 } & G/G & $107(82.3)$ & $67(88.2)$ & Additive & $0.60(0.27-1.32)$ & 0.19 \\
\hline & & $\mathrm{G} / \mathrm{A}$ & $21(16.1)$ & $9(11.8)$ & Dominant & $0.63(0.27-1.45)$ & 0.27 \\
\hline & & $\mathrm{A} / \mathrm{A}$ & $2(1.5)$ & $0(0)$ & Recessive & $0.00(0.00-\mathrm{NA})$ & NA \\
\hline & & G & $235(90.4)$ & $143(94.1)$ & & 1 & \\
\hline & & A & $25(9.6)$ & $9(5.9)$ & & $0.59(0.27-1.30)$ & 0.19 \\
\hline & \multirow{5}{*}{ rs3135831 } & $\mathrm{C} / \mathrm{C}$ & $65(50)$ & $36(47.4)$ & Additive & $0.91(0.60-1.39)$ & 0.67 \\
\hline & & $\mathrm{C} / \mathrm{T}$ & $46(35.4)$ & $35(46)$ & Dominant & $1.17(0.66-2.07)$ & 0.60 \\
\hline & & $\mathrm{T} / \mathrm{T}$ & $19(14.6)$ & $5(6.6)$ & Recessive & $0.41(0.15-1.15)$ & 0.07 \\
\hline & & $\mathrm{C}$ & $176(67.7)$ & $107(70.4)$ & & 1 & \\
\hline & & $\mathrm{T}$ & $84(32.3)$ & $45(29.6)$ & & $0.88(0.57-1.36)$ & 0.57 \\
\hline
\end{tabular}

Bold characters represent statistically significant values $(P<0.05 / 4)$.

Previous studies reported that FGFRs were abundantly expressed in the normal prostate [11-14], and that the expression of FGFR1 and FGFR2 was elevated in prostates of $\mathrm{BPH}$ patients [16-18]. To our knowledge, there are no reports indicating that the expression of FGFR1 or FGFR2 is upregulated or downregulated according to the alleles of rs1047100 and rs13317. However, rs13317 could be involved in regulating expression considering that it is located in the $3^{\prime}$ UTR which modifies stability and transport of mRNA as well as translation efficiency [31], and whose SNPs are well known to increase the efficiency of $3^{\prime}$ end processing [32]. In addition, although rs1047100 is synonymous SNP, recent studies reported that synonymous SNPs play an important role in protein activities and specificities without influencing amino acid sequences [33, 34]. Thus, we postulated that FGFR1 and FGFR2 might be overexpressed in BPH but that the expression of FGFR1 and FGFR2 might be relatively low in $\mathrm{BPH}$ patients with genotypes containing the $\mathrm{A}$ allele of rs1047100 or the C allele of rs13317 compared to BPH patients without those. Furthermore, a previous study showed that rs13317 of FGFR1, which plays a role in wound healing and is a positive regulator of skeletal formation [35], was associated with delayed bone healing after bone fracture and, in particular, that the frequency of the $\mathrm{C}$ allele of rs13317 in FGFR1 was increased in individuals with delayed bone healing compared to those with uneventful healing [36]. However, in that study, no significant associations were observed between $F G F$ polymorphisms and delayed bone healing [36]. Thus, they suggested the possibility that specific alterations in the receptor, despite FGFs functions, may be involved in triggering the pathologic process during fracture healing [36]. Given this report, we also postulated that rs13317 may affect the activity of FGFR1. Thus, FGFR1 activity may be relatively decreased in BPH patients with the $\mathrm{C}$ allele of rs13317, resulting in lower and slower progression of BPH in those individuals. Further studies are needed to determine how FGFR1 and FGFR2 polymorphisms affect their expression and/or activity in BPH progression.

The major limitation of our study was the small sample size used for comparison within BPH subgroups. However, this is the first genetic study on the relationship between SNPs of FGFR1 and FGFR2, and BPH. Our results revealed associations between FGFR1 and FGFR2, and the clinical phenotypes of BPH. Further studies with a larger sample sizes are needed to validate our results.

\section{Conclusions}

In conclusion, we found that polymorphisms of FGFR1 and FGFR2 were not associated with BPH. However, clinical analysis revealed that a FGFR2 polymorphism was associated with 
prostate volume and a FGFR1 polymorphism was associated with IPSS in BPH patients. These results suggest that FGFR1 and FGFR2 may be related to BPH severity and progression.

\section{Conflict of Interests}

The authors declare that they have no conflict of interests.

\section{Acknowledgment}

This work was supported by a Grant from Kyung Hee University in 2013 (KHU-20130169).

\section{References}

[1] G. Kramer, D. Mitteregger, and M. Marberger, "Is benign prostatic hyperplasia (BPH) an immune inflammatory disease?" European Urology, vol. 51, no. 5, pp. 1202-1216, 2007.

[2] G. Untergasser, S. Madersbacher, and P. Berger, "Benign prostatic hyperplasia: age-related tissue-remodeling," Experimental Gerontology, vol. 40, no. 3, pp. 121-128, 2005.

[3] N. A. Bhowmick, E. G. Neilson, and H. L. Moses, "Stromal fibroblasts in cancer initiation and progression," Nature, vol. 432, no. 7015, pp. 332-337, 2004.

[4] K. L. Lee and D. M. Peehl, "Molecular and cellular pathogenesis of benign prostatic hyperplasia," Journal of Urology, vol. 172, no. 5, pp. 1784-1791, 2004.

[5] D. M. Peehl and R. G. Sellers, "Cultured stromal cells: an in vitro model of prostatic mesenchymal biology," Prostate, vol. 45, pp. 115-123, 2000.

[6] Z. Li, T. Habuchi, N. Tsuchiya et al., "Increased risk of prostate cancer and benign prostatic hyperplasia associated with transforming growth factor-beta 1 gene polymorphism at codon10," Carcinogenesis, vol. 25, no. 2, pp. 237-240, 2004.

[7] M. D. Omrani, S. Taghipour-Bazargani, S. Salari-Lak, and M. Bagheri, "Association of codon 10 polymorphism of the transforming growth factor beta 1 gene with prostate cancer and hyperplasia in an iranian population," Urologia Internationalis, vol. 83, no. 3, pp. 329-332, 2009.

[8] R. J. Mullan, E. J. Bergstralh, S. A. Farmer et al., "Growth factor, cytokine, and vitamin D receptor polymorphisms and risk of benign prostatic hyperplasia in a community-based cohort of men," Urology, vol. 67, no. 2, pp. 300-305, 2006.

[9] N. Tsuchiya, L. Wang, Y. Horikawa et al., "CA repeat polymorphism in the insulin-like growth factor-I gene is associated with increased risk of prostate cancer and benign prostatic hyperplasia," International journal of oncology, vol. 26, no. 1, pp. 225-231, 2005.

[10] R. Grose and C. Dickson, "Fibroblast growth factor signaling in tumorigenesis," Cytokine and Growth Factor Reviews, vol. 16, no. 2, pp. 179-186, 2005.

[11] M. Ittman and A. Mansukhani, "Expression of fibroblast growth factors (FGFs) and FGF receptors in human prostate," Journal of Urology, vol. 157, no. 1, pp. 351-356, 1997.

[12] F. Sinowatz, W. Amselgruber, D. Lincoln et al., "Role of basic fibroblast growth factor in prostatic tumors," Nutrition, vol. 11, no. 5, pp. 619-621, 1995.

[13] M. S. Steiner, "Role of peptide growth factors in the prostate: a review," Urology, vol. 42, no. 1, pp. 99-110, 1993.
[14] C. Saez, A. C. Gonzalez-Baena, M. A. Japon et al., "Expression of basic fibroblast growth factor and its receptors FGFR1 and FGFR2 in human benign prostatic hyperplasia treated with finasteride," Prostate, vol. 40, pp. 83-88, 1999.

[15] F. Ropiquet, D. Giri, B. Kwabi-addo, A. Mansukhani, and M. Ittmann, "Increased expression of fibroblast growth factor 6 in human prostatic intraepithelial neoplasia and prostate cancer," Cancer Research, vol. 60, no. 15, pp. 4245-4250, 2000.

[16] S. Boget, C. Cereser, P. Parvaz, A. Leriche, and A. Revol, "Fibroblast growth factor receptor 1 (FGFR1) is over-expressed in benign prostatic hyperplasia whereas FGFR2-IIIc and FGFr3 are not," European Journal of Endocrinology, vol. 145, no. 3, pp. 303-310, 2001.

[17] A. Hamaguchi, I. Tooyama, T. Yoshiki, and H. Kimura, "Demonstration of fibroblast growth factor receptor-I in human prostate by polymerase chain reaction and immunohistochemistry," Prostate, vol. 27, no. 3, pp. 141-147, 1995.

[18] H. Y. Leung, P. Mehta, L. B. Gray, A. T. Collins, C. N. Robson, and D. E. Neal, "Keratinocyte growth factor expression in hormone insensitive prostate cancer," Oncogene, vol. 15, no. 9, pp. 1115-1120, 1997.

[19] Z. Ma, N. Tsuchiya, T. Yuasa et al., "Polymorphisms of fibroblast growth factor receptor 4 have association with the development of prostate cancer and benign prostatic hyperplasia and the progression of prostate cancer in a Japanese population," International Journal of Cancer, vol. 123, no. 11, pp. 2574-2579, 2008.

[20] P. Siami, C. G. Roehrborn, J. Barkin et al., "Combination therapy with dutasteride and tamsulosin in men with moderate-tosevere benign prostatic hyperplasia and prostate enlargement: the CombAT (Combination of Avodart and Tamsulosin) trial rationale and study design," Contemporary Clinical Trials, vol. 28, no. 6, pp. 770-779, 2007.

[21] S. A. Kaplan, J. D. McConnell, C. G. Roehrborn et al., "Combination therapy with doxazosin and finasteride for benign prostatic hyperplasia in patients with lower urinary tract symptoms and a baseline total prostate volume of $25 \mathrm{Ml}$ or greater," Journal of Urology, vol. 175, no. 1, pp. 217-220, 2006, discussion 220-211.

[22] C. G. Roehrborn, P. Boyle, D. Bergner et al., "Serum prostatespecific antigen and prostate volume predict long-term changes in symptoms and flow rate: results of a four-year, randomized trial comparing finasteride versus placebo," Urology, vol. 54, no. 4, pp. 662-669, 1999.

[23] J. D. McConnell, R. Bruskewitz, P. Walsh et al., "The effect of finasteride on the risk of acute urinary retention and the need for surgical treatment among men with benign prostatic hyperplasia," The New England Journal of Medicine, vol. 338, no. 9, pp. 557-563, 1998.

[24] S. J. Jacobsen, D. J. Jacobson, C. J. Girman et al., "Natural history of prostatism: risk factors for acute urinary retention," Journal of Urology, vol. 158, no. 2, pp. 481-487, 1997.

[25] H. B. Shim, J. K. Lee, T. Y. Jung, and J. H. Ku, "Serum prostatespecific antigen as a predictor of prostate volume in Korean men with lower urinary tract symptoms," Prostate Cancer and Prostatic Diseases, vol. 10, no. 2, pp. 143-148, 2007.

[26] Y.-L. Chang, A. T. L. Lin, K.-K. Chen et al., "Correlation between serum prostate specific antigen and prostate volume in Taiwanese men with biopsy proven benign prostatic hyperplasia," Journal of Urology, vol. 176, no. 1, pp. 196-199, 2006.

[27] J. B. Anderson, C. G. Roehrborn, J. A. Schalken, and M. Emberton, "The progression of benign prostatic hyperplasia: 
examining the evidence and determining the risk," European Urology, vol. 39, no. 4, pp. 390-399, 2001.

[28] M. Emberton, E. B. Cornel, P. F. Bassi, R. O. Fourcade, J. M. F. Gómez, and R. Castro, "Benign prostatic hyperplasia as a progressive disease: a guide to the risk factors and options for medical management," International Journal of Clinical Practice, vol. 62, no. 7, pp. 1076-1086, 2008.

[29] E. D. Crawford, S. S. Wilson, J. D. McConnell et al., "Baseline factors as predictors of clinical progression of benign prostatic hyperplasia in men treated with placebo," Journal of Urology, vol. 175, no. 4, pp. 1422-1426, 2006.

[30] J. Carballido Rodríguez, X. Badia Llach, A. Gimeno Collado, L. Regadera Sejas, R. Dal-Ré Saavedra, and M. Guilera Sardá, "Validity of tests for initial diagnosis and its concordance with final diagnosis in patients with suspected benign prostatic hyperplasia," Actas Urologicas Espanolas, vol. 30, no. 7, pp. 667674, 2006.

[31] S. Di Marco, Z. Hel, C. Lachance, H. Furneaux, and D. Radzioch, "Polymorphism in the 3 /-untranslated region of TNF $\alpha$ mRNA impairs binding of the post-transcriptional regulatory protein HuR to TNF $\alpha$ mRNA," Nucleic Acids Research, vol. 29, no. 4, pp. 863-871, 2001.

[32] N. H. Gehring, U. Frede, G. Neu-Yilik et al., "Increased efficiency of mRNA 3/ end formation: a new genetic mechanism contributing to hereditary thrombophilia," Nature Genetics, vol. 28, no. 4, pp. 389-393, 2001.

[33] A. A. Komar, "Silent SNPs: impact on gene function and phenotype," Pharmacogenomics, vol. 8, no. 8, pp. 1075-1080, 2007.

[34] C. Kimchi-Sarfaty, J. M. Oh, I.-W. Kim et al., "A "silent" polymorphism in the MDR1 gene changes substrate specificity," Science, vol. 315, no. 5811, pp. 525-528, 2007.

[35] K. Ishizeki, H. Saito, T. Shinagawa, N. Fujiwara, and T. Nawa, "Histochemical and immunohistochemical analysis of the mechanism of calcification of Meckel's cartilage during mandible development in rodents," Journal of Anatomy, vol. 194, no. 2, pp. 265-277, 1999.

[36] J. M. Guimaraes, I. C. Guimaraes, M. E. Duarte et al., "Polymorphisms in BMP4 and FGFR1 genes are associated with fracture non-union," Journal of Orthopaedic Research, vol. 31, no. 12, pp. 1971-1979, 2013. 


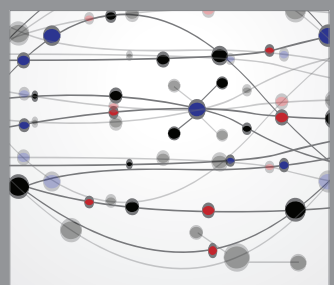

The Scientific World Journal
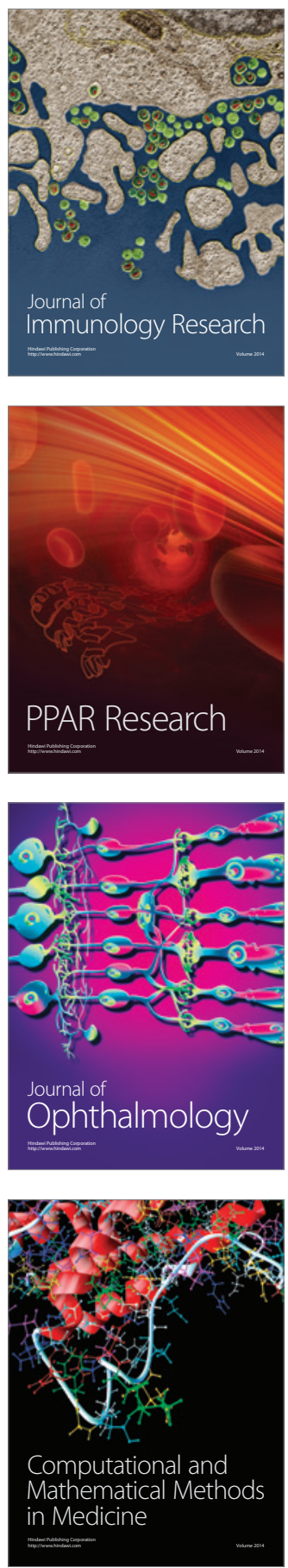

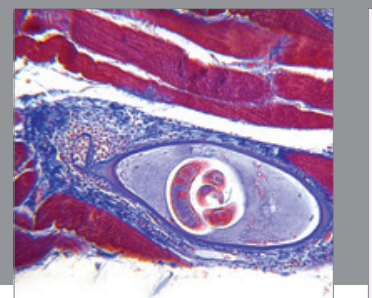

Gastroenterology

Research and Practice
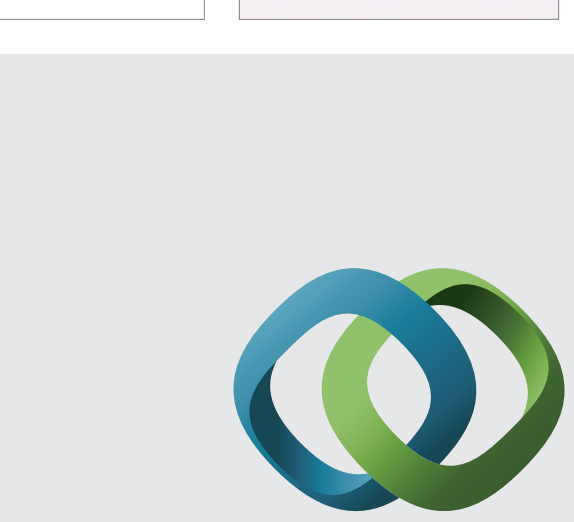

\section{Hindawi}

Submit your manuscripts at

http://www.hindawi.com
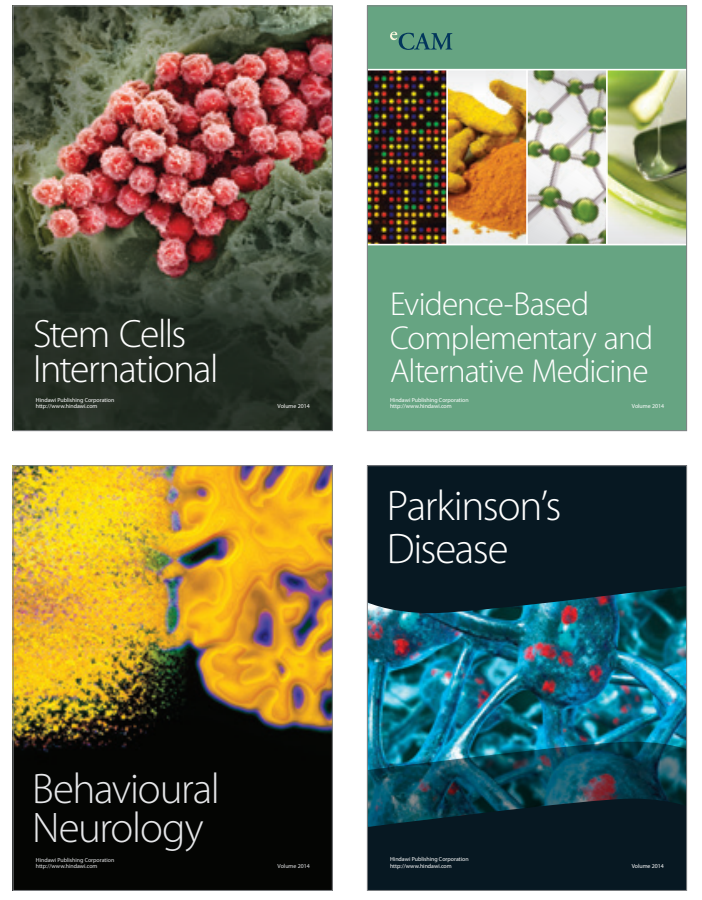
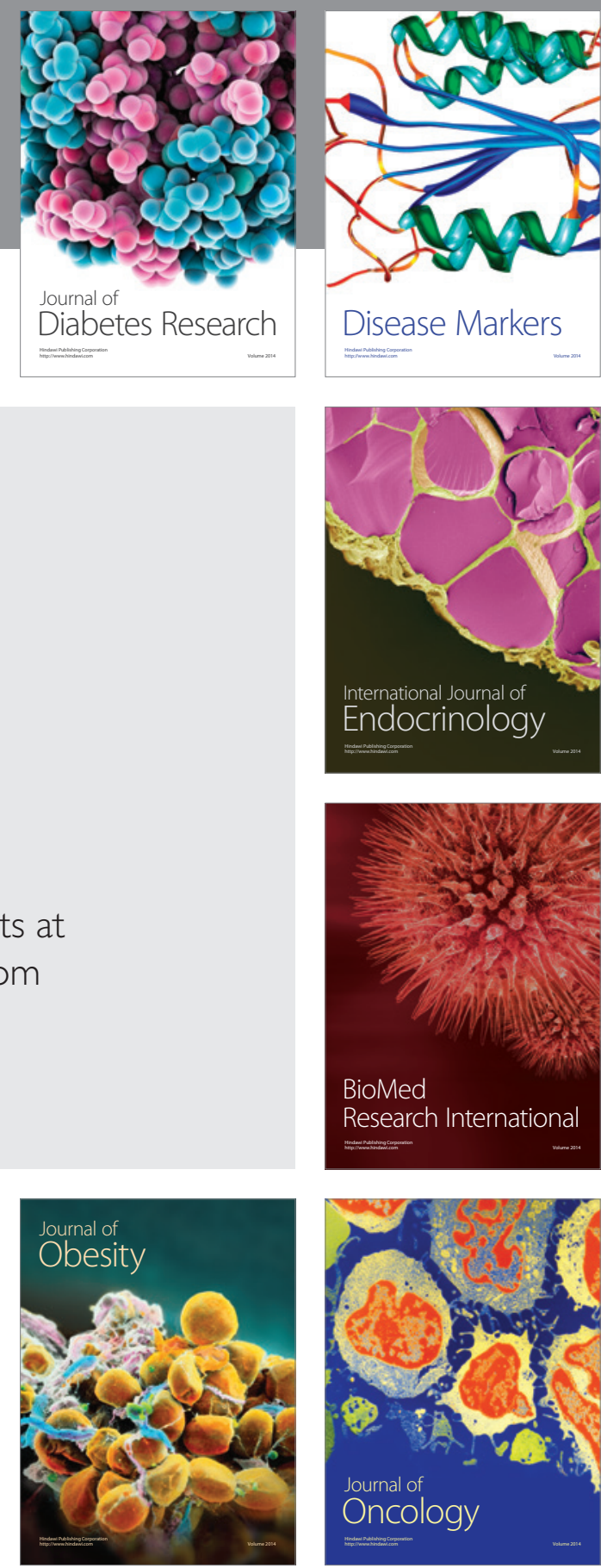

Disease Markers
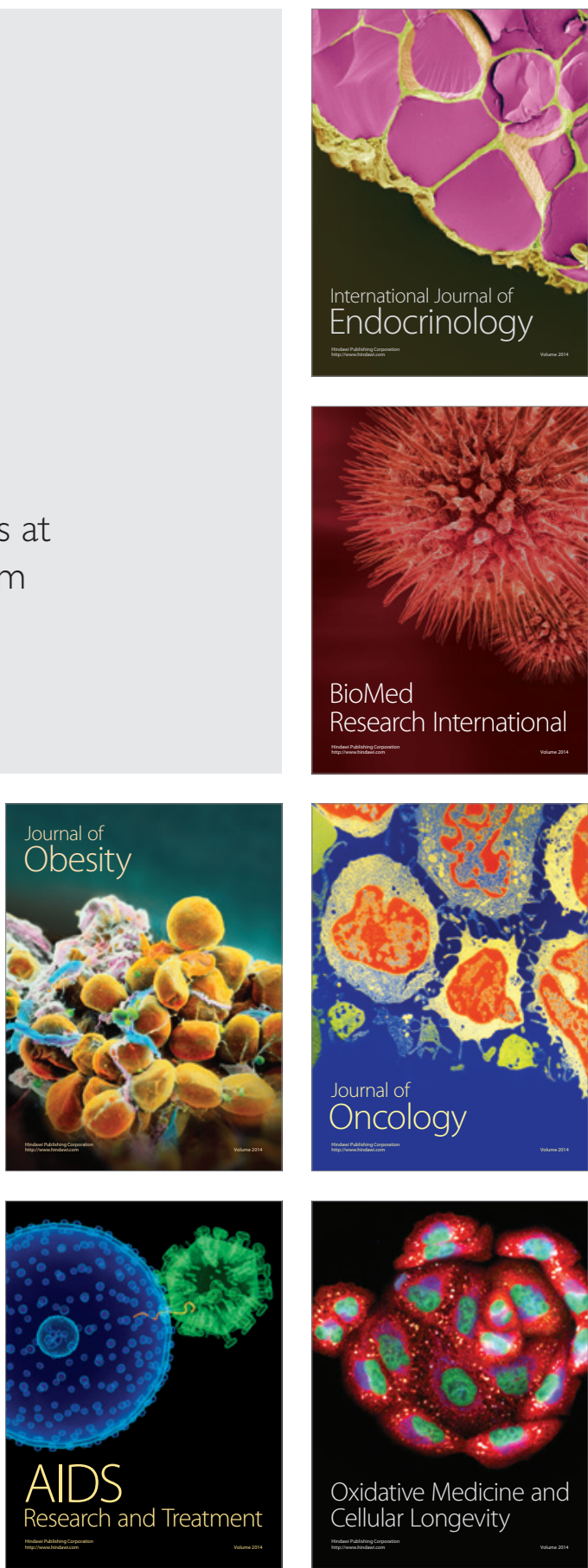